\title{
Antonio Ros de Olano, Director General de Infantería, Artillería y Sanidad Militar
}

\author{
Alonso de Vega $\mathrm{JM}^{\mathrm{a}}{ }^{1}$
}

Sanid. mil. 2015; 71 (3): 205-209; ISSN: 1887-8571

\begin{abstract}
RESUMEN
Llamado "el general prudente", Antonio Ros de Olano fue un personaje muy conocido en su época. Destacó como militar y político, participando en batallas y levantamientos. Como escritor, publicó libros de memorias sobre episodios militares y fue un precursor de la narrativa fantástica en España. Fue amigo de Espronceda, Campoamor, Larra y muchos otros que participaron en la famosa tertulia del "El Parnasillo" en café del Príncipe de Madrid. En su vertiente política, fue ministro de Isabel II, diputado y senador vitalicio. En su carrera militar, ascendió a Teniente General y entre sus numerosos cargos, fue Director General de Sanidad Militar.
\end{abstract}

PALABRAS CLAVE: Sanidad Militar. Historia. Uniformología.

Antonio Ros de Olano, Director General of Infantry, Artillery and Military Health Services.

SUMMARY: Called "the prudent general," Antonio Ros de Olano was a character well known in his time. He stood out as a soldier and politician, participating in battles and uprisings. As a writer, he published books of memoirs about military episodes and was a precursor of the fantastic literature in Spain. He was a friend of Espronceda, Campoamor, Larra and many others who participated in the famous gathering of "The Parnasillo" in 'El Café del Príncipe' of Madrid. In the political aspect, he was minister of Isabel II, deputy and senator. In his military career, he was appointed lieutenant general and among his numerous positions, he was Director General of Military Health Services.

KEY WORDS: Military Medical Corps. History. Uniformology.

\section{UN CARAQUEÑO AL SERVICIO DE LA CORONA}

Antonio Ros de Olano y Perpiñá fue un hombre frío y sereno como militar, y elocuente y apasionado como político y escritor. A lo largo de su vida supo hacer de "la terquedad" una virtud que le llevó a alcanzar los más elevados reconocimientos profesionales y sociales. Nació en Caracas, Venezuela, el 9 de noviembre de 1808, cuando las tropas de Napoleón invadían España. Hijo de un militar destinado en la Capitanía General de Venezuela, abandonó aquella tierra con cinco años de edad, tras producirse la proclamación de independencia. En España, vivió durante su infancia en una finca llamada Las Olivas que su familia paterna poseía en Gerona ${ }^{1}$.

La vocación militar de Antonio Ros de Olano, como la del que sería su gran amigo y compañero de armas, el general Juan Prim, fue muy temprana: a los 18 años era alférez de infantería en el Real Cuerpo de la Guardia del Rey Fernando $\mathrm{VII}^{2}$. Su bautismo de fuego se produjo en 1834, en Alsasua, en la feroz batalla que enfrentó a las tropas de los cristinos con los carlistas. En esa confrontación, resultó herido y tras una larga convalecencia se reincorporó al frente y participó en la batalla de Larremiar ${ }^{3}$. Sus acciones ante el enemigo, y el haber desempeñado satisfactoriamente el cargo de ayudante del general Mina, hicieron que fuera ascendido a teniente coronel y en 1837 , con tan solo 29 años, a coronel ${ }^{4}$.

General de Brigada Médico. Inspección General de Sanidad. Madrid. España.

Dirección para correspondencia: jalode@oc.mde.es

Recibido: 7 de mayo de 2015

Aceptado: 9 de junio de 2015
La meteórica carrera militar vino también acompañada de una activa experiencia política. Como militar se mostraba cauto y reflexivo, pero como hombre político era un liberal y encendido orador, y como escritor daba rienda suelta a su imaginación siendo uno de los precursores de la narrativa fantástica en España ${ }^{5}$.

En 1839 fue elegido diputado con carácter independiente. En los años siguientes sería reelegido, mientras consolidaba su carrera militar ${ }^{6}$.

En 1841 fue destinado a Cartagena. La ciudad ya no ostentaba el protagonismo militar de tiempos pasados y la mayor parte del trabajo consistía en tareas rutinarias. Al disponer de más tiempo libre, Ros de Olano compaginaba sus obligaciones profesionales con actividades particulares en el negocio de la minería de la comarca de Cartagena. Su vinculación a esta zona de Murcia le llevó a adquirir una extensa finca y un caserón con forma de castillo en la localidad de Balsicas. Las propiedades habían pertenecido a la Congregación de San Felipe de Neri y luego, tras la desamortización de Mendizábal, pasaron a ser del Estado. A lo largo de su vida, Ros de Olano pasaría allí muchas temporadas, descansando y entregándose a otra de sus aficiones favoritas: la caza ${ }^{7}$.

En 1843 renunció a su independencia política para declararse simpatizante del partido moderado, contribuyendo al levantamiento de los moderados contra Espartero. Las acciones tuvieron éxito y provocaron el cambio de gobierno, pasando Narváez a ser Presidente del Gobierno en 1844. En correspondencia a ese apoyo político, Narváez le nombró Jefe Superior Político, es decir, Gobernador de Murcia ${ }^{8}$.

No sintiéndose satisfecho con el anterior cargo, retornó a Madrid para entregarse a su carrera política en el Congreso. 
Tuvo fama de orador vehemente, en contraste con su frialdad en el campo de batalla. También empleó su tiempo en Madrid para dedicarse a la literatura9 ${ }^{9}$ Pero Ros de Olano no se apartó, a pesar de todo, de su trayectoria militar. En 1843, bajo el reinado de Isabel II, fue ascendido a general de Infantería y en 1844 obtuvo las insignias de general de división ${ }^{10}$.

De nuevo en el escenario político, en 1847 pasó a ser ministro de la Corona ocupando la cartera de Instrucción y Obras Públicas $^{11}$. Solo permanecería unos meses en ese cargo, ya que por los vaivenes de la política cesó como ministro ${ }^{12}$, y fue promovido a teniente general ${ }^{13}$.

Ya ascendido, se le da la opción de ser nombrado embajador del Reino de España en Portugal o pasar destinado a Ceuta como Capitán General de la recién instituida Capitanía General de África ${ }^{14}$. La vertiente militar prevaleció sobre la política y Ros de Olano se instaló en Ceuta. Desde esa ciudad, recorrió todas las posiciones españolas en África, preocupándose en particular de la creación de lo que hoy llamaríamos una eficaz inteligencia militar y de organizar la infraestructura de una auténtica Sanidad Militar.

En Ceuta, descubrió una conspiración para sublevar la ciudad y entregarla a los ingleses ${ }^{15}$. Tras sofocar la rebelión, permaneció poco tiempo más en aquella ciudad, ya que renunció porque su salud se resentía con el clima. En el momento de partir de África, Ros de Olano no sospechaba que volvería once años más tarde, cuando las circunstancias se deterioraran hasta el punto de que España terminase por declarar la guerra al Sultanato de Marruecos ${ }^{16,17}$.

En octubre de 1848, Isabel II nombró a Ros de Olano Capitán General de Burgos, destino que también tuvo que abandonar prematuramente por una enfermedad "que le ataca al pecho» y se le concedió permiso de dos meses para recuperarse en los baños de La Isabela, en la provincia de Guadalajara ${ }^{18}$

De vuelta a Madrid, transcurrieron unos años dedicándose a escribir y a emprender una nueva trayectoria como hombre de negocios. En Balsicas, cerca de Cartagena, donde poseía las propiedades adquiridas unos años antes, pasó temporadas descansando y practicando la caza. Aprovechó también las estancias en esas tierras murcianas para vigilar sus inversiones en las minas de plata y plomo de la Unión. Por otra parte, se asoció con José de Salamanca para descubrir en las redes de ferrocarriles, que se estaban construyendo entonces, otra fuente de intereses y negocios ${ }^{19}$.

El 24 de septiembre de 1853, fue nombrado Director General de Sanidad Militar ${ }^{20}$. El reglamento en ese año contemplaba una organización del Cuerpo Militar de Sanidad que, bajo la autoridad del Director General de Sanidad, estaba constituida por una Plana Menor o Brigada de Sanidad y una Plana Mayor. Esta última, se componía de médicos y farmacéuticos. Por desgracia, esta ordenación no llegó a consolidarse. Sin embargo, la experiencia de Ros de Olano como Capitán General de África y su preocupación por el estado en que allí se encontraba la Sanidad Militar, le resultó de gran utilidad para mejorar la utilización de los recursos sanitarios durante la guerra de África de 1859 y 1860.

A finales de 1853, el entonces Presidente Sartorius decidió suspender las Cortes indefinidamente y cesar en sus cargos a un buen número de senadores y generales ${ }^{21}$, entre ellos, Ros de Olano, que abandonó la Dirección General de Sanidad Militar, cargo para el que el Presidente Sartorius nombró al Mariscal de Campo D. Ramón Boiguez ${ }^{22}$. Poco más tarde, se produjo un pronunciamiento en la localidad de Vicálvaro realizado por un grupo de militares

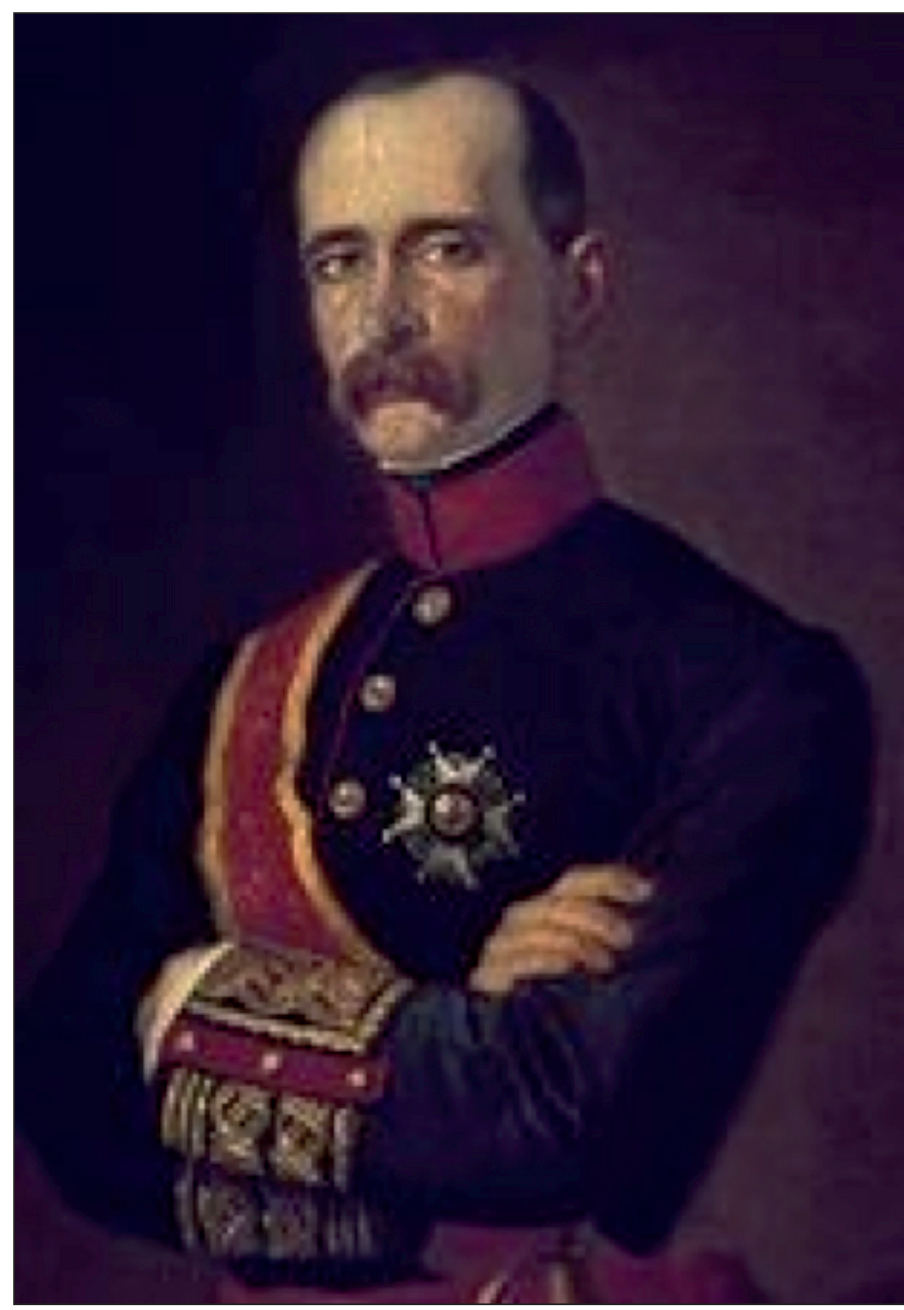

Figura1. El general Ros de Olano, marqués de Guad-el-Jelú. (Imagen tomada de Geneall, http://geneall.net/es/name/602399/antonio-ros-de-olano-1-marques-de-guad-el-jelu)।

entre los que sobresalieron O'Donell, Dulce y Ros de Olano. La revolución triunfó en todo el país y, con Espartero como nuevo Presidente, acabó el gobierno moderado ${ }^{23}$. Ros de Olano no volvió a su anterior puesto de Director General de Sanidad Militar ya que la Reina Isabel II publicó un Real Decreto en el que consideraba que dicho cargo fuera ocupado «por persona que se halle dotada de los conocimientos facultativos, práctica y demás circunstancias necesarias para el mejor acierto en el servicio sanitario del Ejército»; para lo que vino a decretar que el Inspector del Cuerpo de Sanidad Militar, doctor D. Manuel Codorniú Ferreras fuese nombrado Director General del mismo Cuerpo ${ }^{24}$.

Entre 1856 y 58, Ros de Olano, desempeñó sucesivamente los puestos de Director General de Infantería y de Artillería ${ }^{25}$. En esa época, se implantó con carácter oficial la prenda de cabeza que él mismo había diseñado. Conocido con el nombre de su primer apellido, "ros", fue empleado durante unos ochenta años por el Ejército español a pesar de que tuvo sus detractores porque no cubría la nuca ni del sol ni de las inclemencias de la lluvia. El ros se adornaba en la parte delantera con una pequeña granada de latón con una mecha simulada. En los botones que sujetaban a ambos lados el barbuquejo figuraba, junto al escudo monárquico, una leyenda con el nombre del Cuerpo. Así en el de Sanidad, podía leerse: "Sanidad Militar". En la actualidad, 
el ros, de color blanco con esprit de plumas rojas, es usado como prenda de cabeza del uniforme de gala de la Guardia Real26,27.

\section{LA GUERRA DE ÁFRICA DE 1859 Y 1860}

Las cabilas de Anghera habían destruido las fortificaciones que se comenzaron a levantar para proteger Ceuta, derribando además el linde de piedra que servía de límite entre el territorio español y el marroquí. Por otra parte, las tribus del Rif aumentaron en frecuencia e intensidad las agresiones a las fortalezas de Melilla, el Peñón y Alhucemas. Las ofensas, aunque no nuevas, eran graves y llevaron al Presidente del Gobierno, Leopoldo O’Donell, a declarar la guerra.

La guerra duró cuatro meses y se inició en diciembre de 1859 con la invasión del Sultanato de Marruecos, un mes después de que el grueso de las fuerzas hubiera desembarcado en Ceuta. Al mando de todas las fuerzas estaba el propio O’Donell, quien dividió el ejército en tres cuerpos, y puso al frente de ellos a los generales Zavala, Echague y Ros de Olano. Había también un grupo de reserva que mandaba el general Prim y una División de Caballería conducida por el mariscal de campo Alcalá Galiano ${ }^{28}$.

Ros de Olano mandó establecer hospitales generales y hospitales de sangre en Ceuta. En campo abierto, había procurado acampar cerca de fuentes puras de agua, estableciendo rígidas normas para emplear las aguas más limpias para consumo humano. Sin embargo, en Ceuta acamparon entre dos hospitales de coléricos, lo que provocó casi de inmediato una epidemia entre las fuerzas allí establecidas. El mismo Ros de Olano cayó enfermo de cólera y finalmente fue uno de los afortunados que logró sobrevivir, ya que sin duda la principal causa de mortalidad entre nuestras tropas no fue producida por las armas enemigas sino por el cólera y otras enfermedades. Dentro de este aspecto sanitario en la guerra de África, merece la pena comentar también que los médicos españoles se percataron de que los heridos de bala de ciertos frentes comenzaron a sufrir lesiones de mayor gravedad. Esto era debido a que al inicio de las hostilidades los marroquíes utilizaban como arma de fuego la espingarda, cuyo proyectil era redondo. Más tarde, los ingleses suministraron armas al Sultanato de Marruecos y las heridas de bala eran provocadas por proyectiles de forma cónica que causaban heridas más devastadoras ${ }^{29,30}$.

Apenas recuperado del cólera, Ros de Olano participó en uno de los enfrentamientos cruciales contra las fuerzas enemigas. El escenario de esta acción se desarrolló junto al rio Guadel-Jelú, que significa "Rio dulce". Los detalles de aquella batalla quedaron dramáticamente reflejados por la pluma de Pedro Antonio de Alarcón, periodista, escritor y testigo directo: "El General Ros de Olano los dejó acercarse cuanto quisieron, sin inquietarse de sus alaridos, ni de las banderas que ondeaban ante nuestros ojos; pero luego los vio a distancia y apiñados como una manada de ovejas, mandó hacer fuego a la artillería. Yo no he visto nunca puntería tan admirable". En definitiva, la victoria de Guad-el-Jelú contra unas encarnizadas fuerzas hostiles fue decisiva para ganar la batalla de Tetuán ${ }^{31}$.

Concluida la guerra, Isabel II honra a Ros de Olano con los títulos de Marqués de Guad-el-Jelú y el de Vizconde de Ros, que sumaría al de Conde la Almina que la Reina le había concedi- do con anterioridad ${ }^{32}$. En esa época era usual que los monarcas ennobleciesen a militares que habían destacado en el campo de batalla o en otros servicios a la Corona, sin embargo a Ros de Olano nunca le gustó darse a conocer por esos títulos. De regreso a España, pasó a ejercer la Dirección General de Infantería, cargo que había ocupado antes ${ }^{33}$. Además, en julio de 1860 la Reina Isabel II le nombró Comandante General del Real Sitio de San Ildefonso para encargarse de su seguridad personal durante los periodos que pasaba en aquel lugar.

Corrieron después años en que nuestro general repartió su tiempo de una manera más apacible entre sus tareas en la Dirección de Infantería y el Senado, compaginándolo con una mayor dedicación a la literatura. Publicó la colección de Leyendas de África y luego una extraña novela, El Doctor Lañuela. En la línea del género fantástico había escrito ya varios cuentos, que prosiguió con publicaciones de tintes enigmáticos como $\mathrm{La}$ Dama Blanca o El Libro de las lágrimas de Elisa. Muchos años más tarde, terminaría las crónicas de los Episodios Militares. Mantuvo una profunda amistad con Espronceda (que le dedicó su obra de El Diablo Mundo) y otros escritores románticos. Ya antes de la guerra de África, tenía por costumbre acudir a una tertulia, la de El Parnasillo, en el Café del Príncipe, junto al Teatro Español de Madrid, donde también se reunían otros personajes del mundo de la literatura y del arte, tales como Larra, Zorrilla, Campoamor, Hartzenbusch, Mesonero Romanos o de la política, como Bravo Murillo o González Bravo ${ }^{34-37}$.

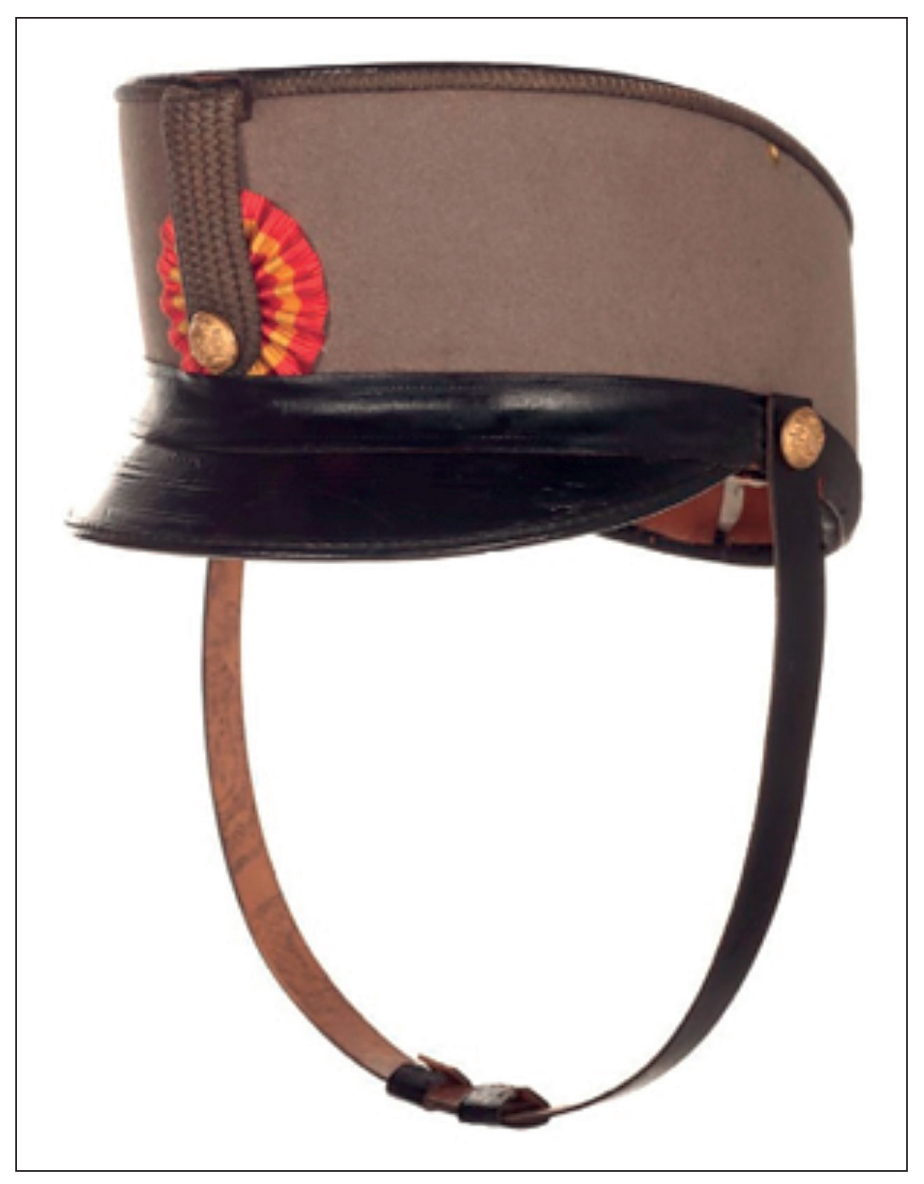

Figura 2. Ros de fieltro gris de cadete. 


\section{REVOLUCIÓN Y RESTAURACIÓN}

En 1868, murió Narváez siendo Presidente del Consejo de Ministros y la Reina Isabel II nombró como sucesor a González Bravo. Su comportamiento rozó desde el principio el absolutismo dictatorial y enseguida se ganó la oposición acérrima de los militares progresistas. Temiendo una conspiración, González Bravo decidió desterrar a estos militares a lugares apartados del epicentro político. Ros de Olano fue destinado al cuartel de Deva, en Guipúzcoa. Al llegar el verano de ese año, la Corte de Isabel II se desplazó al Escorial y luego a una residencia veraniega en San Sebastián. Poco después, el brigadier Topete encabezó la sublevación de la Marina en Cádiz, a la que se unió el general Prim en esa ciudad. Pronto apoyarían este levantamiento otras guarniciones militares de Andalucía. Esto sería el principio de la Revolución de 1868, conocida como La Gloriosa, que acabaría con el destronamiento de Isabel II. En septiembre de ese año, se enfrentaron las tropas sublevadas contra las realistas en la batalla llamada del Puente de Alcolea, Córdoba, que terminó con el triunfo de las primeras y su avance hacia Madrid. El Presidente González Bravo dimitió y se sucedieron una serie de ceses y nombramientos fugaces ${ }^{38}$. En estas azarosas circunstancias, a Ros de Olano, que contaba entonces con 60 años, se le adjudicó la Capitanía General de Madrid. El general acudió entonces a la Puerta del Sol, donde, rodeado por turbas multitudinarias, se arrancó del uniforme los signos de la monarquía, manifestó su adhesión a los sublevados y arengó al pueblo al grito de "¡Viva la libertad y la soberanía nacional!" 39 . Perdida la causa realista, Isabel II se exilió a Francia después de 35 años de reinado. El Gobierno Provisional de Serrano recompensó a Ros de Olano con la Dirección General de Artillería ${ }^{40}$ y el nombramiento de Presidente del Consejo Supremo de la Guerra ${ }^{41}$.

En 1870 las Cortes eligieron por mayoría Rey de España a Don Amadeo de Saboya. Mientras Amadeo de Saboya viajaba a Madrid para tomar posesión del trono, su principal valedor -y amigo íntimo de Ros de Olano-, el General Prim, fue asesinado en el atentado de la calle del Turco. Poco después, Ros de Olano sería parte de la comitiva que en Cartagena, a bordo del buque Numancia, recibía al rey propuesto y le informaba del terrible asesinato de Prim. Dos años más tarde, nuestro general sería uno de las pocas personas que acompañase a Amadeo a la estación de Mediodía en su despedida de España y regreso a su patria, cuando ya se había iniciado la República y al monarca se le denegara hasta una pareja de la guardia civil que le escoltase ${ }^{42}$.

Las Cortes votaron la República el 23 de febrero de 1873 y a lo largo de los once meses que duró hubo explosiones de anarquía y brotes cantonales por todo el país. Los cantones pretendían constituir algo así como una federación de ciudades, siendo Cartagena la primera en proclamarse cantón y la última en rendirse a las tropas gubernamentales ${ }^{43}$.

En el mismo mes de julio de 1873 en que surgían las proclamaciones cantonales, nuestro general celebraba la boda de su hija Isabel Ros de Olano y Quintana, futura Vizcondesa de Ros, con Alfredo de Vega, teniente coronel de Infantería y descendiente de Juan de Vega, capitán de los Ejércitos con Carlos V y virrey de Sicilia con Felipe II ${ }^{44}$.

Durante los meses de la República, Ros de Olano se dedicó a escribir, apartado de toda actividad política. Retomó la narra-

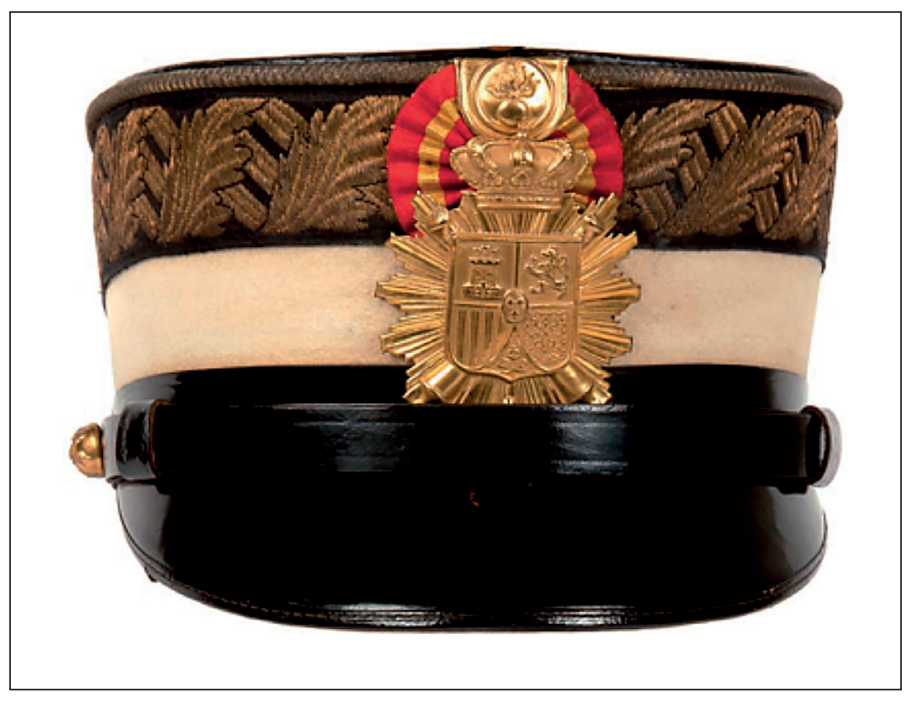

Figura 3. Ros de General de Division.

ción de Jornadas de retorno escritas por un aparecido, libro de memorias que no llegaría a concluir ${ }^{45}$.

A pesar de su carácter prudente y moderado, se unió al grupo constitucionalista que dirigía Sagasta. Durante el periodo de restauración borbónica que siguió a continuación, con Alfonso XII como monarca de España, Sagasta se alternaría sucesivamente en la Presidencia del Gobierno con Cánovas del Castillo, líder del partido conservador.

En 1877 Ros de Olano fue nombrado senador vitalicio, cargo que ocupó hasta su muerte ${ }^{46}$.

\section{ROS DE OLANO Y LA FRANCMASONERÍA}

Existió una estrecha relación entre Ros de Olano y la francmasonería. Desde luego, no era nada de que extrañarse en esos tiempos. Desde la época de represión de Fernando VII, se había ido intensificando una firme tradición de masones en la oficialidad, así como entre famosos políticos e intelectuales. Muchos de los amigos de Ros de Olano, muy conocidos en la vida pública, eran masones: Sagasta, Olázaga, Prim, Zorilla y otros.

La estancia en Barcelona en 1877 acrecentó las relaciones de nuestro general con la masonería. Se reunió con frecuencia con Rosendo Arús, Gran Maestre de la Logia y muy popular posteriormente por haber legado en su testamento una importante suma para la fundación de la biblioteca en Barcelona que lleva su nombre. En esa biblioteca se puede encontrar un ejemplar del último libro que publicó Ros de Olano, poco antes de su muerte, y que dedicó a su amigo Arús.

Tras el fallecimiento de Ros de Olano, su yerno Alfredo de Vega continuaría la estrecha relación con la masonería catalana, llegando a alcanzar el título de Gran Comendador y Gran Maestre del Gran Oriente Nacional ${ }^{47}$.

\section{LOS ULTIMOS AÑOS}

En 1879, con 71 años de edad, Ros de Olano, "el general prudente", no tenía ya el menor deseo de verse envuelto en turbu- 
lencias políticas. Dedicó sus afanes a la literatura, y en lo militar aceptó el nombramiento de presidente para la Junta creada para la redacción de un nuevo Código Militar ${ }^{48}$.

En 1886, antes de morir, entregó al ministro de la Guerra el proyecto ya finalizado de la Ley de Enjuiciamiento Penal Militar. Poco después, presentó un agravamiento del cuadro que venía presentando de debilidad y mareos hasta el punto de obligarle a guardar cama. Se le diagnosticó un tumor cerebral y tras un prolongado proceso en el que se fue apagando poco a poco, falleció en Madrid el 24 de julio de aquel $1886^{49}$.

Antonio Ros de Olano basó sus éxitos militares en la terquedad y en la prudencia. En cierta ocasión le preguntaron sobre la clave de sus victorias en África, a lo que respondió: "Los moros son muy tercos. Todo consiste en ser más tercos que ellos. La terquedad es una gran virtud" 50 .

\section{BIBLIOGRAFIA}

1. López Delgado, J. A. El general Ros de Olano. Ensayo biográfico, bibliográfico y crítico. Vol. I. Artes Gráficas Grapesán S.1. Murcia. 1993, p. 17.

2. Expediente personal de don Antonio Ros de Olano, en el Archivo General Militar de Segovia.

3. Artola Gallego, M. Vidas en tiempo de crisis. Real Academia de la Historia, Madrid, enero, 1999, pp. 262-263.

4. Expediente personal de don Antonio Ros de Olano, en el Archivo General Militar de Segovia.

5. Ros de Olano, A. El diablo las carga, cuadro de costumbres. Imprenta de la Compañía tipográfica. Madrid, 1840.

6. López Delgado Juan Antonio. El general Ros de Olano. Ensayo biográfico, bibliográfico y crítico. Vol. I. Artes Gráficas Grapesán S.L. Murcia. 1993, p. 17.

7. Archivo Municipal de Murcia, leg. 1807: "Relación de fincas rústicas y urbanas de bienes nacionales con expresión de compradores, extensión superficial, etc. 1844. Id. De las vendidas por el crédito público, procedentes de órdenes religiosas y fechas de remate 1837.- Índice alfabético de los poseedores de fincas de bienes nacionales 1837 a 1845 " (carpeta ${ }^{\circ} 12$ ) apéndices VII y VIII.

8. Telégrafo de La Minería (Cartagena), nº 14, 19/7/1843, pp. 6 y7.

9. Pont, J. Mundo Fantástico y visión alegórica en la narrativa de Antonio Ros de Olano. AIH. Actas X, 1989. Centro Virtual Cervantes.

10. Expediente personal de don Antonio Ros de Olano, en el Archivo General Militar de Segovia.

11. Gaceta de Madrid núm. 4768, de 04/10/1847, página 1.

12. Gaceta de Madrid núm. 4799, de 04/11/1847, página 1.

13. Expediente personal de don Antonio Ros de Olano, en el Archivo General Militar de Segovia.

14. Gaceta de Madrid núm. 4847, de 22/12/1847, página 1.

15. Ros de Olano A. Saltos de la memoria (Episodios militares). Madrid. Imprenta de Miguel ginesta., 1844, pp. 195-196.

16. Biblioteca Central Militar: Servicio Histórico Militar, Madrid. Hoja de Servicios de Ros de Olano, fol. 13.

17. Gaceta de Madrid núm. 5040, de 01/07/1848, página 1.

18. Gaceta de Madrid núm. 5157, de 26/10/1848, página 1.

19. López Delgado J. A. El general Ros de Olano. Ensayo biográfico, bibliográfico y crítico. Vol I. Artes Gráficas Grapesán S.1. Murcia. 1993, pp. 216-218.

20. Gaceta de Madrid núm. 267, de 24/09/1853, página 2. Por Real Decreto, el 24 de septiembre de 1853, se nombra al Teniente General D. Antonio Ros de Olano Director General de Sanidad Militar, "vacante por haber sido destinado a una comisión especial del servicio el Mariscal de Campo Don Manuel Monteverde, que anteriormente lo era".

21. Tusell J., Sánchez Mantero R. Historia de España. Vol. 12. El siglo XIX. De la Guerra de la Independencia a 1868.Espasa Calpe. Austral. 2004, pp. 450-453

22. Gaceta de Madrid num. 345, de 11 de diciembre de 1853, página 1.

23. Gaceta de Madrid num. 546, de 30 de junio de 1854, página 1.

24. Gaceta de Madrid núm. 614, de 7 de septiembre de 1854, página 1. Real Decreto de Isabel II en que se puede leer: «Tomando en consideración la conve- niencia del que el mando superior y dirección del cuerpo de Sanidad militar se ejerza por persona que se halle dotada de los conocimientos facultativos, práctica y demás circunstancias necesarias para el mejor acierto en el servicio sanitario del ejército, vengo a decretar lo siguiente: Artículo $1^{\circ}$ : quedan derogados los artículos $4^{\circ}$ y $10^{\circ}$ del reglamento del Cuerpo de Sanidad militar del 5 de abril de 1853 . Artículo $2^{\circ}(\ldots)$ Artículo $3^{\circ}$ : Atendiendo a los méritos, servicios y demás circunstancias que concurren en el Inspector médico del cuerpo de Sanidad militar D. Manuel Codorniú y Ferreras, vengo a nombrarle Director general del mismo cuerpo. Dado en Palacio (...). Está rubricado de Real mano.- El ministro de la Guerra, Leopoldo O’Donell».

25. Gaceta de Madrid num.1249, de 5 de junio de 1856, página 1.

26. Almirante y Torroella J. Diccionario militar, etimológico, histórico, tecnológico. Imprenta y litografía del depósito de la Guerra. Madrid 1869, página 288

27. A la cabeza del Ejército. Prendas de cabeza del Ejército de Tierra en el Museo. Catálogo general de publicaciones oficiales. http://publicacionesoficiales.boe. es Editor, 2012.

28. Tusell J., Sánchez Mantero R. Historia de España. Vol. 12. El siglo XIX. De la Guerra de la Independencia a 1868. Espasa Calpe. Austral.2004, pp. 666-673.

29. De Alarcón P. A. Diario de un testigo de la Guerra de África. Madrid. Imprenta y librería de Gaspar y Roig., editores. 1859, pág. III.

30. Gómez Rodríguez L. La Sanidad Militar en la Guerra de África. Sanid. Mil. Vol. 69 no. 2. Madrid, abr-jun 2013.

31. Rueda A. El enemigo "invisible" de la Guerra de África (1859-60) y el proyecto histórico del nacionalismo español: Del Castillo Alarcón y Landa. The Colorado Review of Hispanic Studies. Vol. 4, Fall 2006, pp. 147-167.

32. Gaceta de Madrid núm. 82 , de 22 de marzo de 1860, página 1

33. Gaceta de Madrid núm. 111, de 20 de abril de1860, página 1.

34. Vallejú Márquez Y. Los territorios de la transgresión: Naturalezas deformadas en los cuentos de Antonio Ros de Olano. (Grupo de Estudiosdel Siglo XVIII). Cuadernos de Ilustración y Romanticismo, $\mathrm{n}^{\circ}$ 4-5 (1997), pp.131-149.

35. Ros de Olano A. El ánima de mi madre (Cuento Fantástico). El Iris. Semanario Enciclopédico. (1841): 10-13; 31-35; 51-56; 82-87.

36. Espronceda José de. El diablo mundo. Biblioteca universal. www.biblioteca. org.ar. Ed. Del Cardo. 2006.

37. Bartolomé Martínez C. La noche de las máscaras, de Ros de Olano: cuando lo fantástico se viste de carnal. 2009. Ensayos sobre ciencia ficción y literatura fantástica: actas del Primer Congreso Internacional de literatura fantástica y ciencia ficción (1, 2008, Madrid). Teresa López Pellisa y Fernando Ángel Moreno Serrano (eds.). Madrid: Asociación Cultural Xatafi: Universidad Carlos III de Madrid, 2009, p. 331-344

38. Tusell J., Sánchez Mantero R. Historia de España. Vol.13. Revolución y Restauración. Del sexenio revolucionario a la guerra de Cuba (1868-1898). Espasa Calpe. Austral.2004, pp. 666-673 pp. 11-34.

39. Rivas Santiago N. Politicos, gobernantes y otras figuras españolas. Páginas de mi archivo y apuntes para mis memorias. Una página inédita de la revolución de setiembre. Madrid, Francisco Beltrán, Librería Española y Extranjera., I Edición, 1933, pp. 111-112.

40. Gaceta de Madrid núm. 4, de 04/01/1874, página 25.

41. Gaceta de Madrid núm. 6, de 06/01/1874, página 45.

42. REGION DE MURCIA DIGITAL. Antonio ros de Olano. http://www.regmurcia.com/servlet/s.Sl?sit=c,373,m,1207\&r=ReP-13010-DETALLE_REPORTAJES. Consulta 22 de Abril de 2015.

43. Cano Ruiz Tomás. El Cantón de Cartagena. Grupo Cultural de Estudios sociales de Melbourne y Acracia Publications. Agosto 2012

44. Lopez Delgado Juan Antonio. El general Ros de Olano. Ensayo biográfico, bibliográfico y crítico. Vol I. Artes Gráficas Grapesán S.l. Murcia. 1993, p. 404.

45. Pont Jaume (Ed.) Narrativa fantástica en el siglo XIX. España e Hispanoamérica. Milenio, 1997.

46. Real Decreto de 10 de abril de 1877.

47. Benimeli Ferrer José Antonio. Masonería española contemporánea. Vol. II. Desde 1868 hasta nuestros días. Siglo XXI de España Editores., S.A., Madrid, 1980, p.p.1-2

48. Ros de Olano Antonio. Prólogo al Código Penal del ejército. Tomo I. Madrid, Imprenta a cargo de J. Quesada, 1885, pp V-X (Biblioteca Central Militar: servicio Histórico Militar. Madrid).

49. Biblioteca Central Militar: servicio Histórico Militar. Madrid. Hoja de servicios de ros de Olano, fol. 331.

50. Rico de Estasen José. Un general romántico. Gloria y memoria del primer marqués de Guad-el-Jelú. ABC. Madrid, 23 de Agosto de 1959. 